\title{
THE USE OF A BUSINESS GAME TO IMPROVE DECISION-MAKING PROCESS IN MANAGEMENT
}

\author{
Paulino Silva ${ }^{1}$, Ricardo Mello ${ }^{2}$, Fabiane Mello ${ }^{2}$ \\ ${ }^{1}$ CICE \& CECEJ - ISCAPIIPP (PORTUGAL) \\ ${ }^{2}$ Centro Universitário de Sul de Minas - UNIS-MG (BRAZIL)
}

\begin{abstract}
In competitive business environments as the ones we live today, it is even more important for a manager to make better decisions. The classical model of decision making assumes managers have access to all the information needed to reach a decision. So, managers can make their decisions by ranking their preferences among existing alternatives. Unfortunately, it is very common that managers do not have access to all needed information to decide. Incomplete information leads to a high risk in the decision-making process. However, worse than that is not knowing what to do even having the information needed to decide. In this paper we present some lessons learned from the experience of the utilization of a Business Game at ISCAP/IPP, as a result of a partnership with UNIS-MG, a Brazilian University from Minas Gerais. For this study, a qualitative research approach was in place, since we used qualitative methods, mainly observation and semi-structured interviews. ISCAP/IPP is a business school of higher education that provides diverse programmes of studies in business areas: accounting and management, marketing, international commerce, business communication, secretary management, etc. Nevertheless, students miss some skills related with the decision-making process in management. In this learning experience students from different backgrounds improve their decision-making process in several ways: i) improve their knowledge about the organization; ii) understand the mind frame (from the background) used by colleagues to make their decisions; iii) interpret formal and informal documents available not only internally (such as financial statements), but also externally (such as macroeconomic projections and market reports); iv) realize that a manager needs to be more that an accountant or marketer, but most of times a mix of different backgrounds at the same time.
\end{abstract}

Keywords: Business Game, Decision-Making Process, Management, Financial Information.

\section{INTRODUCTION}

The main problem of the research is how the teaching of business management can be streamlined through electronic simulations (business games). These simulations allow interaction among the teams, in which participants perform multivariable analysis considering internal and external environments so that they can make decisions in a simulated business world.

The contextualization of this study is done through a case study presenting the training of students through a business game held in ISCAP-IPP (Portugal) in conjunction with the University Center UnisMG (Brazil), and has been held since 2013 in an annual basis.

This approach is justified by the fact that information is becoming more and more a competitive advantage and the basis for an effective decision-making process is able to provide an intelligent management. The professional who is not ready for decision-making can jeopardize the company's results. Traditional teaching methodologies do not enrich the knowledge in the same way simulation does. Through a business game approach, participants who are involved within the simulation, gain experience and are prepared for making their future decisions in the labor market.

It is also important to emphasize the contribution of the business game for future managers allowing them to transform data into knowledge which may generate strategies for their companies in order to get the best results. 